\title{
Liver function status in male wister rats treated with ethanol extract of the leaves of nauclea latifolia owing to aluminum chloride-induced oxidative
}

\section{stress}

\begin{abstract}
Aim: The goal of this study is to determine the protective effects of $N$. latifolia ethanol leaf extracts against toxicity caused by aluminum chloride $\left(\mathrm{AlCl}_{3}\right)$ in male rats.

Materials and methods: Twenty male albino rats were randomly divided into four groups of five animals and studied over a 7-day period. The first group served as the control and received only normal feed and water, Group 2 received $\mathrm{AlCl}_{3}(100 \mathrm{mg} / \mathrm{kg}$ bw) daily. Group 3 received $100 \mathrm{mg} / \mathrm{kg}$ bw ethanol extract of $N$. latifolia an hour after administration of $100 \mathrm{mg} /$ $\mathrm{kg} \mathrm{AlCl}_{3}$. Group 4 was treated with only ethanol extract of $N$. latifolia $(100 \mathrm{mg} / \mathrm{kg}$ bw).

Results: Thiobarbituric acid reactive substances (TBARS), bilirubin, alanine aminotransferase, aspartate aminotransferase and full blood count were significantly ( $\mathrm{p}<$ $0.05)$ changed in rats treated with $\mathrm{AlCl}_{3}(100 \mathrm{mg} / \mathrm{kg} \mathrm{bw})$. The results obtained indicate that the extracts were beneficial in ameliorating damages caused by $\mathrm{AlCl}_{3}$ in male rats.

Conclusion: This study clearly showed the protective effects of $N$. latifolia extracts on liver mal-function by aluminum chloride induced in male rats. The obtained results indicated that the $N$. latifolia at $100 \mathrm{mg} / \mathrm{kg}$ bw would be a good natural source for protection against malfunctioning of the liver in male rats.
\end{abstract}

Keywords: liver function, wister rats, ethanol extract, nauclea latifolia, aluminum chloride, oxidative stress
Volume 3 Issue 6 - 2016

\author{
Yakubu OE \\ Department of Biochemistry, Federal University Wukari, \\ Nigeria
}

Correspondence: Yakubu OE, Department of Biochemistry, Faculty of Pure and Applied Sciences, Federal University Wukari, Nigeria,Email oj4real_2007@yahoo.co.uk

Received: September 27, 2016 | Published: December 14, 2016 $\begin{array}{lllr}\text { Abbreviations: } & \mathrm{AlCl}_{3}, & \text { aluminum } & \begin{array}{r}\text { chloride; } \\ \text { TBARS, thiobarbituric }\end{array} \text { acid } \\ \text { reactive } & \text { substances; }\end{array}$ EDTA, ethylenediaminetetraacetic acid; AST, aspartate aminotransferase; ALT, alanine aminotransferase; ALP, alkaline phosphatase; FBC, full blood count; ANOVA, analysis of variance: WBC, white blood cell; RBC, red blood cell

\section{Introduction}

Nauclea latifolia is a widely distributed shrub or tree that is found in the forest and fringe tropical forests in northern Nigeria and other African countries. Medicinal uses of this plant vary from one traditional setting to another and includes: fever, pain, dental cavities, septic mouth, malaria, dysentery, diarrhea, and diseases of the central nervous system such as epilepsy. ${ }^{1}$

The leaves of $N$. latifolia have been used in folk medicine for the treatment of malaria, hypertension, diarrhea, tuberculosis, dysentery and also as laxative. ${ }^{2}$ The root extract is also reported to have neuropharmacological and anti-hyperglycemic effects and has been used in the management of diabetes and treatment of diseases of the central nervous system such as epilepsy, depression and anxiety. The decoction in water exhibited anti- parasitic potential and the aqueous extract is used against chloroquine resistance strains of Plasmodium falciparum. ${ }^{3}$ The hot aqueous and ethanol extracts also exhibited a high anti-bacterial property. ${ }^{4}$

The decoction of the leaves is recommended for stomach upset, especially in children. ${ }^{5}$ The decoction along with alligator pepper is used for cough, cold and general weakness of the body. The fruit is used to treat hemorrhoids, dysentery, colic and menstrual disorder, while the stem and root bark are used in Nigeria to arrest pre-term contraction in pregnant women. ${ }^{5}$

\section{Materials and methods}

\section{Sample collection and preparation}

The leaves of the plant ( $N$. latifolia) were collected from the Biological garden of Federal University Wukari, Nigeria. The leaves were examined to ensure that they were disease-free and only healthy plant parts were used. The leaves were thoroughly washed with clean water and dried under shade for 3 weeks to reduce moisture content. The dried leaves were pulverized using a laboratory blender.

\section{Sample extraction}

One hundred gram $(100 \mathrm{~g})$ of the powdered leaf was soaked in ethanol $(500 \mathrm{ml})$ in the ratio $(1: 5 \mathrm{w} / \mathrm{v})$ with intermittent shaking for exactly $48 \mathrm{hrs}$. The extract was filtered out first using a clean white sieving mesh and Whatman No. 1 filter paper. The filtrates were concentrated using a thermostat water cabinet at $40^{\circ} \mathrm{C}$ for 7 days. The concentrated extracts were then transferred to air-tight containers in the refrigerator at $4^{\circ} \mathrm{C}$ until administration.

\section{Animals specimen}

Twenty (20) male albino rats of 100-150g were obtained from the animal house of the Department of Biochemistry, Faculty of Pure and Applied Sciences, Federal University Wukari, Nigeria. All experiments were conducted in compliance with ethical guide for care and use of laboratory animals of the Faculty of Pure and Applied Sciences, Federal University Wukari, Nigeria. 


\section{Experimental design}

The rats were randomly divided into four groups $(n=5)$ and the extract was administered to the albino rats orally with the aid of oral cannula.

1. Group 1: Normal Control: Received only normal feed and water daily.

2. Group 2: $\mathrm{AlCl}_{3}$ Control: Received $100 \mathrm{mg} / \mathrm{kg}$ bw Aluminium chloride daily.

3. Group 3: Received $100 \mathrm{mg} / \mathrm{kg}$ bw ethanol extract of N. latifolia leaves an hour after the administration of $100 \mathrm{mg} / \mathrm{kg}$ bw of Aluminium chloride.

4. Group 4: Received $100 \mathrm{mg} / \mathrm{kg}$ bw ethanol extract of N. latifolia leaves only.

5. After the experimental period, animals were sacrificed and venous blood was collected by cardiac puncture and their liver was harvested. Blood samples were collected into EDTA tubes for the plasma and plain sample tubes containing no anticoagulant for the serum. The blood samples were allowed to clot and the serum was obtained by centrifuging at $3,000 \mathrm{rpm}$ for $5 \mathrm{~min}$. The tissues were weighed and homogenized using a standard laboratory mortar and pestle. The homogenates were centrifuged and the supernatant examined for Thiobarbituric acid reactive substance (TBARS)

\section{Tissue preparation}

Weighed liver and kidney samples were homogenized separately in 10 parts $(\mathrm{w} / \mathrm{v})$ of ice-cold $50 \mathrm{mM}$ Tris- $\mathrm{HCl},(\mathrm{pH}$ 7.4) using a homogenizer (Janke and Kunkel Germany). The homogenates were centrifuged at $3,000 \mathrm{rpm}$ for $15 \mathrm{~min}$ and the supernatants were collected and used for measurement of lipid peroxidation (TBARS)

\section{Biochemical determinations}

Thiobarbituric acid reactive substances (TBARS): Hepatic lipid peroxidation was determined as thiobarbituric acid reactive substances as described by Torres et al., ${ }^{6}$ Lipid peroxidation generates peroxide intermediates which upon cleavage release malondialdehyde, a product which react with thiobarbituric acid. The product of the reaction is a colored complex which absorbs light at $535 \mathrm{~nm}$. The extinction coefficient, $1.56 \times 10-5 \mathrm{M}-1 \mathrm{Cm}-1$ was used in the calculation of TBARS and values were expressed as nmol $/ \mathrm{ml}$.

Aspartate aminotransferase (AST): Aspartate aminotransferase was determined as described by Reitman et al., ${ }^{7}$ using assay kits (Randox Laboratories Ltd, UK). Aspartate aminotransferase (AST) catalyzes the transamination of aspartate to alpha-ketoglutarate to form glutamate and oxaloacetate, which then reacts with 2,4-dinitrophenylhydrazine to form hydrazone derivative of oxaloacetate, a colored complex which can be measured at $546 \mathrm{~nm}$

Alanine aminotransferase (ALT): Alanine aminotransferase was determined as described by Reitman et al., ${ }^{7}$ using assay kits (Randox Laboratories Ltd, UK). Alanine aminotransferase (ALT) catalyzes the transamination of alanine to alpha-ketoglutarate to form glutamate and pyruvic acid, which then reacts with 2,4-dinitro-phenylhydrazine to form hydrazone derivative of pyruvate, a colored complex which can be measured at $546 \mathrm{~nm}$.

Alkaline phosphatase (ALP): Serum alkaline phosphatase was determined as described by Klein et al., ${ }^{8}$ Serum alkaline phosphatase catalyzes the hydrolysis of a colorless substrate of phenolphthalein monophosphate giving rise to phosphoric acid and phenolphthalein which, at alkaline $\mathrm{pH}$ turns into a pink color that can be determined photo-metrically at $550 \mathrm{~nm}$.

Serum bilirubin: This was determined colorimetrically according to the method described by Jendrassic et al., ${ }^{9}$ using assay kits (Randox Laboratories Ltd, UK). Conjugated bilirubin reacts with diazotized sulfanilic acid in alkaline medium to form a blue complex. Total bilirubin is determined in the presence of caffeine, which releases albumin bound bilirubin, by the reaction with diazotized sulfanilic acid.

Potassium ion: The amount of potassium is determined by using sodium tetraphenylboron in a specifically prepared mixture to produce a colloidal suspension. ${ }^{10}$ The turbidity of which is proportional to potassium concentration in the range of $2-7 \mathrm{mEq} \backslash \mathrm{L}$.

Full blood count (FBC): A full blood count analysis was carried out to determine the volume of blood cells present in the whole blood sample. This was performed using the Abacus 380 Auto Hematology Analyzer. The machine then counts the type of cells via two types of sensors; detectors and electrical impedance.

Statistical analysis: Statistical analysis of the results was done using the SPSS statistical software version 20. The results were analyzed using Analysis of Variance (ANOVA). The Post-Hoc test was carried out using a significance level of 0.05 .

\section{Results and Discussion}

\section{Effect of the extract and $\mathrm{AICl}_{3}$ on liver enzyme activity}

Data obtained showed significant $(\mathrm{p}<0.05)$ increase in ALT, AST, ALP and bilirubin in rats treated with $\mathrm{AlCl}_{3}$ compared to normal control. Hence, treatment of the intoxicated animals with the extracts was able to significantly reduce $(\mathrm{p}<0.05)$ these anomalies to normal when compared to the normal control. Also, treatment of normal animals caused non-significant increase/decrease in these parameters (Table 1).

\section{Effect of the extract and $\mathrm{AlCl}_{3}$ on hematological parameters}

Hematological parameters (Table 2) in $\mathrm{AlCl}_{3}$ intoxicated rats, shows that there was significant decrease $(p<0.05)$ in HGB, PCV and PLT in the groups intoxicated with only $\mathrm{AlCl}_{3}$ while $\mathrm{WBC}$ and $\mathrm{RBC}$ levels were non-significant $(\mathrm{p}>0.05)$ as compared with the control. Treatment of intoxicated animals with the extract significantly increased HGB, PCV and PLT levels but was insignificant ( $p>0.05$ ) with WBC and RBC compared to normal control.

\section{Effect of the extract and $\mathrm{AICl}_{3}$ on TBARS}

The results obtained showed significant increase $(\mathrm{p}<0.05)$ in TBARS in the $\mathrm{AlCl}_{3}$ control group compared to normal control. Treatment of intoxicated animals with the extract resulted in significant decrease $(p<0.05)$ in TBARS level compared with both normal control and $\mathrm{AlCl}_{3}$ control groups. Treatment of normal animals with the extract caused non-significant increase/decrease in TBARS concentration. Non-significant increase/decrease ( $p>0.05)$ was observed in $\mathrm{K}+$ concentration across all groups of both treated and untreated animals (Table 3 ). 
Table I Effects of $\mathrm{N}$. latifolia ethanol extract on some liver enzymes of $\mathrm{AICl}_{3}$ treated rats

\begin{tabular}{lllll}
\hline Group & ALT (U/L) & AST (U/L) & BIL (mg/dl) & ALP (U/L) \\
\hline N. Control & $18.43 \pm 0 I .49 a$ & $052.00 \pm 10.25 a$ & $019.20 \pm 05.58 \mathrm{a}$ & $078.58 \pm 10.10 \mathrm{ab}$ \\
\hline $\mathrm{AICl3} \mathrm{Control}$ & $47.00 \pm 10.15 \mathrm{c}$ & $283.75 \pm 56.48 \mathrm{c}$ & $052.88 \pm 06.64 \mathrm{c}$ & $277.00 \pm 11.56 \mathrm{c}$ \\
\hline $\mathrm{AICl} 3+\mathrm{N} . \mathrm{L}$ & $19.16 \pm 07.27 \mathrm{a}$ & $066.25 \pm 07.15 \mathrm{~b}$ & $041.26 \pm 09.22 \mathrm{~b}$ & $081.25 \pm 24.2 \mathrm{lb}$ \\
\hline Normal + N.L & $24.78 \pm 03.83 \mathrm{~b}$ & $056.00 \pm 10.83 \mathrm{ab}$ & $015.94 \pm 05.34 \mathrm{a}$ & $057.75 \pm 10.34 \mathrm{a}$ \\
\hline
\end{tabular}

Each value represents the mean \pm SD of 5 Rats. N.L = Nauclea latifolia.

Groups with same superscript in the column are considered non-significant different at $p<0.05$.

Groups with different superscripts in the same the column are significantly different at $p<0.05$.

Table 2 Effects of N. latifolia ethanol extract on some hematological analysis of $\mathrm{AlCl}_{3}$ treated male rats

\begin{tabular}{|c|c|c|c|c|c|}
\hline Group & WBC (x I09/L) & 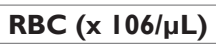 & HGB (g/dL) & PCV (\%) & PLT (x I 03/ $\mu \mathrm{l})$ \\
\hline N. Control & $8.55 \pm 2.04 a$ & $6.90 \pm 1.04 a$ & $13.75 \pm 2.69 b$ & $47.33 \pm 06.65 b$ & $310.50 \pm 35.17 c$ \\
\hline $\mathrm{AICl} 3$ Control & $8.78 \pm 1.69 a$ & $5.06 \pm 1.37 \mathrm{a}$ & $10.60 \pm 0.72 \mathrm{a}$ & $39.78 \pm 04.83 a$ & $229.25 \pm 20.2 \mathrm{la}$ \\
\hline N. + N.L & $5.35 \pm 1.95 a$ & $5.67 \pm 0.70 a$ & $13.43 \pm 1.78 b$ & $49.55 \pm 04.57 b$ & $260.00 \pm 30.23 b$ \\
\hline
\end{tabular}

Each value represents the mean \pm SD of 5 Rats. N.L = Nauclea latifolia.

Groups with same superscript in the column are considered non-significant different at $p<0.05$

Groups with different superscripts in the same the column are significantly different at $p<0.05$.

Table 3 Effect of $N$. latifolia ethanol extract on TBARS and $\mathrm{K}+$ Level in $\mathrm{AlCl}_{3}$ intoxicated male rats

\begin{tabular}{lll}
\hline Group & TBARS $(\mathbf{n m o l} / \mathbf{m l})$ & $\mathbf{K}+(\mathbf{m g} / \mathbf{d l})$ \\
\hline $\mathrm{N}$. Control & $0.05 \pm 0.03 \mathrm{a}$ & $09.50 \pm 0 \mathrm{I} .00 \mathrm{a}$ \\
\hline $\mathrm{AlCl} 3$ Control & $0.24 \pm 0.0 \mathrm{lc}$ & $08.00 \pm 00.90 \mathrm{a}$ \\
\hline $\mathrm{AlCl} 3+\mathrm{N} . \mathrm{L}$ & $0.09 \pm 0.0 \mathrm{lb}$ & $09.50 \pm 02.00 \mathrm{a}$ \\
\hline Normal + N.L & $0.08 \pm 0.05 \mathrm{~b}$ & $09.50 \pm 0 \mathrm{I} .00 \mathrm{a}$ \\
\hline
\end{tabular}

Each value represents the mean \pm SD of 5 Rats. N.L = Nauclea latifolia.

Groups with same superscript in the column are considered non-significant different at $p<0.05$.

Groups with different superscripts in the same the column are significantly different at $p<0.05$.

\section{Discussion}

The present study was carried out to investigate the protective effect of ethanol extract $N$. latifolia on aluminum-chloride $\left(\mathrm{AlCl}_{3}\right)$ induced liver and biochemical alterations in male rats. Data obtained showed significant $(\mathrm{p}<0.05)$ increase in ALT, AST, ALP and Bilirubin in rats treated with $\mathrm{AlCl}_{3}(100 \mathrm{mg} / \mathrm{kg})$ compared to Normal Control. These observations are similar to the data reported by Abdel and Zabut. $^{11}$

In the present study, the activities of AST and ALT were significantly increased in rats administered $\mathrm{AlCl}_{3}$. This may be due to the leakage of the enzymes from the liver cytosol in to the blood stream and low liver dysfunction and disturbances in the biosynthesis of these enzymes with alteration in the permeability of liver membrane. ${ }^{12}$ Aluminum exposure can result in aluminum accumulation in the liver and this metal can be toxic to the hepatic tissue at high concentrations. ${ }^{13}$

Cellular membranes contain polyunsaturated fatty acids susceptible to the action of free oxygen radicals that initiate membrane lipid peroxidation, thus leading to disturbances in the structure and function of cells. ${ }^{14,15}$ Lipid aldehydes generated during breakdown of lipid superoxides are especially dangerous to the organism. These aldehydes, although less reactive than superoxides, can easily migrate at a considerable distance and have a longer (a few minute) half-life. Therefore, lipid aldehydes can react with other molecules far away from the site of their origin. ${ }^{15}$ In this study there was an increase in liver TBARS level because $\mathrm{AlCl}_{3}$ and the plant extract are metabolized in the liver in the presence of cytochrome P450-dependent mixed function monooxygenases, which hydroxylate organophosphates to hydrophilic intermediary products. ${ }^{16}$ These intermediary products are conjugated with endogenous compounds, mainly with glucuronic acid, and excreted with urine. ${ }^{17}$

Hematological parameters (Table 2) in $\mathrm{AlCl}_{3}$ intoxicated rats, showed that there was significant decrease $(\mathrm{p}<0.05)$ in HGB, PCV and PLT in the groups intoxicated with only $\mathrm{AlCl}_{3}$ while $\mathrm{WBC}$ and $\mathrm{RBC}$ levels were non-significant $(\mathrm{p}>0.05)$ as compared with the control. Treatment of intoxicated animals with the extract significantly increased HGB, PCV and PLT levels but non-significantly $(\mathrm{p}>0.05)$ those of $\mathrm{WBC}$ and $\mathrm{RBC}$ compared to normal control. The present result is in accordance with previous studies by Polenakovic et al., ${ }^{18}$

\section{Conclusion}

This study clearly showed the protective effects of $N$. latifolia extracts on liver mal-function in aluminum chloride-induced toxicity in male rats. The obtained results indicated that the $N$. latifolia at $100 \mathrm{mg} / \mathrm{kg}$ bw would be a good choice of natural source for protection against liver toxicity.

\section{Acknowledgments}

None.

\section{Conflicts of interest}

Author declares there are no conflicts of interest.

\section{Funding}

None. 


\section{References}

1. Amos S, Abbah J, Chindo B. Neuropharmacological effects of the aqueous extract of $N$ latifolia root bark in rats and mice. Journal of Ethnopharmacology. 2005;97(1):53-57.

2. Andissa ON, Miguel ML, Etou AW, et al. Determination of blood indices of albino rats treated with aluminum chloride. Pak J Biol Sci. 2004;7:1613-1615.

3. Vical BF, Valentin A, Cournac V, et al. In vitro antiplasmodial activity of stem and root extracts of Nauclea latifolia S.M. (Rubiaceae). J Ethnopharmacol. 1998;61(3):173-178.

4. Okiei W, Ogunlesi M, Osibote EA, et al. Comparative study of the antimicrobial activity of components of different polarities from the leaves of $N$. latifolia. Res J Med Plant. 2011;5:321-329.

5. Duke JA. Ethnobotanical uses of $N$. latifolia Phytochem \& Ethnobotanical data bases. Res J Med. 2008;34(12):589-593.

6. Torres SH, De Sanctis JB, De L, et al. Inflammation and nitric oxide production in skeletal muscle of type II diabetic patients. J Endocrinol 2004;181(1):419-427.

7. Reitman S, Frankel S. A colorimetric method for the determination of sGOT and sGPT. American Journal of Clinical Pathology. $1957 ; 28: 56-63$

8. Klein B, Read PA, Babson LA. Rapid Method for the Quantitative Determination of Serum Alkaline Phosphatase. Clinical Chemistry. 1960;6(3):269-275.

9. Jendrassic L, Groff P. Quantitative determination of total and direct bilirubin. Biochem. 1938;297:81.
10. Terri AE, Sesin PG. Determination of serum potassium by using sodium tetraphenylboron.American Journal of Clinical Pathology. 1958;29:86-90.

11. Abdel AIIS, Zabut BM. Determination of blood indices of albino rats treated with aluminum chloride and investigation of antioxidant effects of vitamin E and C. Egyptian Journal of Biology. 2011;13:1-7.

12. Hassoun EA, Stohs SJ. Comparative studies on oxidative stress as a mechanism for the fetotoxic of TCDD, endrin and lindane in C57BL/6 and DBA/2J mice. Teratology. 1995;51:186-192.

13. Yousef MI, Salam AF. Propolis protection from reproductive toxicity caused by aluminium chloride in male rats. Food Chem Toxicol. 2009;47(6):1168-1175.

14. Droge W. Free radicals in the physiological control of cell function. Physiol Rev. 2002;82(1):47-95.

15. Akhgari M, Abdoll AM, Kebry AAA, et al. Biochemical evidence forfree radical induced lipid peroxidation as a mechanism forsubchronic toxicity of malathion in blood and liver of rats. Hum Exp Toxicol . 2003;22(4):205-211.

16. Hussain LA, Jakoniuk MJ, Rogalska J. Assessment of lipid peroxidation in rat tissues in subacute chlorfenvinphos administration. Polish $J$ of Environ Stud. 2007;16(2):233-236.

17. Aminski M, Bankowsk AM, Plewk A, et al. Influence of age on picture of liver damage induced by chlorfenvinphos. Acta Pol Toxicol .1996;4:15.

18. Polenakovic M, Dzekova P, Sikole A. Hepatitis C in dialysis patients Sec Biol Med Sci. 2007;1:239-265. 